\title{
Religion, Psychiatry, and Alternate Sexuality
}

\author{
D Darmansjah, G Kalra, A Ventriglio
}

\begin{abstract}
Religious institutions tend to display a conservative view towards individuals with alternate sexuality or identity. For managing patients with alternate sexuality, it is imperative that clinicians understand and take into account religious views and its effects on a person's mental health. We review the literature on religion, alternate sexuality, and psychiatry to ascertain their interaction and impact on the mental health of individuals with alternate sexuality or identity. Differing but overlapping perspectives on alternate sexuality persist across world religions. Individuals with conflict between religious and sexual identities are prone to have adverse mental health outcomes; adequate social supports result in more positive mental health outcomes. Education on lesbian, gay, bisexual, transgender, queer, and intersex-related topics in mental health professionals leads to better recognition of the issue and provision of respectful, effective mental health care within the context of socio-religious identity and background.
\end{abstract}

Key words: Gender dysphoria; Religion and sex; Sexuality

Debby Darmansjah, MBBS, Latrobe Regional Hospital, Traralgon, Victoria, Australia

Gurvinder Kalra, FRANZCP, MD, MBBS, Flynn Adult Inpatient Psychiatric Unit, Latrobe Regional Hospital (LRH), LRH Mental Health Services, Victoria, Australia

Antonio Ventriglio, $M D, P h D$, University of Foggia, Foggia, Italy

Address for correspondence: $D r$ Gurvinder Kalra, Flynn Adult Inpatient Psychiatric Unit, Latrobe Regional Hospital (LRH), LRH Mental Health Services, Victoria, Australia.Email: kalragurvinder@gmail.com

Submitted: 5 June 2017; Accepted: 10 January 2018

\section{Introduction}

Religion and spiritualism are significant factors that shape human behaviours, beliefs, values, and pathways into care. Religious traditions and doctrines tend to influence social norms by defining acceptable beliefs and attitudes related to sexuality. Alternate sexuality is defined as a form of sexuality that is non-heterosexual (ie, lesbian, gay, bisexual, transgender, queer, and intersex [LGBTQI]). Most religions, especially monotheistic religions have a conservative view of sexual identity, behaviour, and functioning. Individuals facing a dilemma between their religious and sexual identities may experience conflict throughout their lives. Often, such individuals seek help from mental health professionals. Thus, perspectives from psychiatrists play a role in how society deals with alternate sexuality over time.

The LGBTQI rights movement is progressing in both Western and Eastern countries. In 2013, the Sex Discrimination Act 1984 in Australia was amended to criminalise discrimination on the basis of a person's sexual orientation, gender identity, and intersex status. ${ }^{1}$ In Australia, transgender people are able to choose their preferred gender regardless of medical intervention, and intersex people are able to mark their gender as ' $x$ ' in their passports.

In India, in 2018, consensual sexual activities between non-heterosexual individuals were decriminalised. ${ }^{2}$ However, reports of homosexual men being tortured persist in places like Indonesia and Chechnya. In the Aceh province of Indonesia, Sharia - the religious law that forms part of the Islam tradition - permits these acts of violence to occur. There are news reports of lashing of two men found to be in bed together. ${ }^{3}$ It is vital to consider whether religion has any bearing on alternate sexuality, and whether it correlates with mental health.

\section{Religious Views on Alternate Sexuality}

Different religious institutions have different responses towards alternate sexuality. ${ }^{4} \mathrm{~A}$ 'rejecting punitive' approach describes an openly hostile and completely rejecting attitude towards LGBTQI people, whereas a 'full acceptance' approach considers homosexuality to be a normal expression of human intimacy and welcomes LGBTQI people. In a 'qualified acceptance' approach, homosexuality is deemed tolerable but inferior to heterosexuality. ${ }^{4}$

The Catholic Church welcomes homosexual people but teaches that homosexual acts are sinful. ${ }^{5}$ It considers transgender people to be their biological sex, constituting a 'qualified acceptance' response. ${ }^{6}$ Protestant denominations have a broader range of views on the matter and support LGBTQI people with movements like ordaining the 'first openly gay' minister in $1972 .{ }^{7}$ The teachings of the prophet Muhammed through the Qur'an are interpreted as prohibition of any sexual acts between same-sex members of Islamic faith. ${ }^{8}$ In Indonesia, being gay and Muslim is considered 'ungrammatical'. ${ }^{9}$ Nonetheless, Islamic officials in Iran support surgical operation to correct gender dysphoria. ${ }^{10}$ 
In polytheistic religions such as Hinduism, many gods engage in non-heterosexual unions and present with characteristics of both genders. In narratives such as the Ramayana, the 'third gender' (hijra) has long been portrayed as engaged in begging or in sex work. In 2014, the India Supreme Court ruled to support and emphasise the need for access to equal opportunities for transgender people. ${ }^{11}$ In Sikhism, although alternate sexuality remains controversial, the Guru Granth Sahib does not explicitly prohibit homosexuality. Transgender people are accepted in the community, and liberal Sikhs support re-interpretation of Sikh scriptures. ${ }^{12}$ In Sikh scriptures, the human soul is described as being of neither gender, which can be interpreted in the light of contemporary understanding of gender. In Buddhism in Thailand, the 'third gender' (kathoey) is not illegal. Buddha's teachings through the Five Precepts do not negatively target LGBTQI people nor prohibit LGBTQI people from being Buddhist monks. ${ }^{13}$ This is an example of a 'full acceptance' response to alternate sexuality. Nonetheless, these examples are based on generalisation; differing views may exist within each religious denomination.

Cultural and geographical aspects should also be considered when dealing with religious affiliation and sexual identity. Countries with a predominantly Muslim population tend to be 'less tolerant' of homosexuality than countries with a mainly Christian population. ${ }^{14}$ In addition, countries with a large proportion of non-religious population tend to be more tolerant towards homosexuality. ${ }^{14}$ This perceived tolerance and acceptance may precipitate individuals with alternate sexuality to change their religion. The Private Lives survey in Australia found that approximately $60 \%$ of LGBTQI people who were brought up with a Christian religious affiliation claimed to have 'no religion' at the time of the survey. ${ }^{15}$

\section{Psychiatry and Alternate Sexuality}

The earlier versions of DSM described homosexuality as 'sociopathic personality disturbance' and 'sexual deviation'. In 1973, DSM III removed these descriptions owing to the evolving perspectives on alternate sexuality. ${ }^{16}$ Comparably, 'gender identity disorder' from DSM IV-TR was reclassified as 'gender dysphoria' in DSM V, shifting from labelling it as a disorder or clinical problem to highlighting the incongruence between the expressed and assigned genders. ${ }^{17}$

For ICD-11, the World Health Organization proposes deletion of the diagnosis of "psychological and behavioural disorders associated with sexual development and orientation'. This includes 'sexual maturation disorder', 'ego-dystonic sexual orientation', 'sexual relationship disorder', 'other psychosexual development disorders', and 'psychosexual development disorder, unspecified'; all are listed in the current ICD-10. ${ }^{18}$ This change is recommended so that the needs of people with same-sex orientation may be justifiably met. ${ }^{18}$ The ever-expanding societal values and views on alternate sexuality continue to influence psychiatry practice, with a hope to better understand the mental health needs of LGBTQI people.

\section{Confluence}

LGBTQI people are not only stigmatised and physically abused; they are also at increased risk of developing mental illnesses. ${ }^{19}$ A systematic review reported that lesbian, gay and bisexual people are at higher risk ( $>1.5$ times) of developing depression and anxiety disorders over a period of 12 months or lifetime. ${ }^{20}$ The risk profile is similar to that of alcohol and substance dependence. Lifetime prevalence of any substance disorder is higher in lesbian and bisexual women, whereas lifetime prevalence of suicide attempt is higher in gay and bisexual men. ${ }^{20} 62 \%$ of male-to-female and $55 \%$ of female-to-male transgender individuals are depressed, and $32 \%$ of each group attempted suicide. ${ }^{21}$ The strongest predictor of suicide attempts was a previous attempt of suicide. ${ }^{22}$ Over a 12 month-period, participants who had a history of suicidal attempt had $>10$ times greater odds of making another attempt. ${ }^{22}$

The Meyer minority stress model ${ }^{23}$ proposed that a hostile conflict within the social environment could induce major stress that leads to adverse health outcomes in individuals with alternate sexuality. Among LGBTQI people, minority stress was reported to be associated with psychological distress. ${ }^{23}$ The underlying concept of minority stress is based on a belief that the stressors are unique to the stigmatised individuals. ${ }^{23}$ The stressors can be further compounded when a sexual minority individual encounters a conflict within the individual's religious identity, resulting in greater adverse mental health outcomes.

In 2010, a Hong Kong study reported substantial workplace discrimination among the sexual minority population. ${ }^{24}$ Almost a third of the participants reported to have experienced workplace discrimination over a 5-year period; discrimination is associated with psychological distress in the form of increased internalised homophobia. ${ }^{24}$ In India, more than half of the participants identifying as homosexual men were reported to have psychiatric morbidity in the form of somatic symptoms, anxiety/ insomnia, social dysfunction or severe depression. ${ }^{25}$

Although religiosity serves as a protective factor against adverse mental health outcomes particularly in adolescents, the extent of religiosity is negatively correlated with attitudes toward homosexuality. ${ }^{26}$ Many LGBTQI youth have encountered bullying, harassment, rejection, discrimination, and ostracism in public places, schools, and at home. Some leave their 'non-accepting' religions and join spiritual traditions such as paganism or Wicca, which tend to promote full acceptance of sexual diversity. ${ }^{27,28}$

Across most religious affiliations, LGBTQI youth are more likely to report active suicidal ideation than nonLGBTQI youth. ${ }^{29}$ Youth with alternate sexuality who belong to religious affiliations that oppose same-sex marriage also report more depressive symptoms than those who belong 
to religious affiliations that support same-sex marriage. ${ }^{30}$ Furthermore, the conflict that drives an adolescent to leave a religion is associated with higher odds of suicidal thoughts and twice the odds of suicide attempt. ${ }^{26}$ In addition, adverse mental health outcomes persist from early adulthood to middle and late adulthood, at least among transgender individuals. $^{31}$

\section{Way Forward}

Health care professionals may intentionally or unintentionally subject minority patients to stereotypes and discrimination. This may be due to personal biases stemming from sociocultural background, religious and political inclinations, or lack of training, knowledge, or understanding of the issue. A study involving 6540 transgender people reported that $28 \%$ of participants experienced verbal harassment in a doctor's office, $19 \%$ reported being refused medical care because of the transgender status, and $50 \%$ reported having to teach their health providers about their health needs as transgender individuals. ${ }^{32}$

Stigma reduction strategies as part of hospital or medical training include formal or informal teaching sessions on identifying mental health needs of patients with alternate sexuality and addressing the basic LGBTQIrelated terminology. Awareness of the matter can be increased by attending specific conferences or having guest speakers to discuss emerging issues. Mandatory attendance of these activities ensure exposure to the lesson in medical trainees. This is especially crucial for psychiatrists and mental health professionals to whom LGBTQI people present with psychiatric issues. Although teaching may change knowledge, it may not affect attitudes or behaviour; education efforts must be supported by legal frameworks.

At the University of California Davis, a proposed curriculum model on 'culture, gender, LGBT, religion, and spirituality' for psychiatric registrars aims to improve knowledge in this field to provide better care of sexual minority patients who are in conflict with their religiosity. ${ }^{33}$ The lack of knowledge or discomfort in the topic leads to poorer provision of care in this patient population. For psychiatrists, recognising that such conflict may arise in individuals with a sexual and religious identity clash is the initial step towards understanding their mental health needs. A study examining psychiatrists in India revealed an overall positive attitude towards managing homosexual patients, regardless of the age, gender, and experience of the psychiatrists. ${ }^{34}$ There are attempts to sensitise psychiatric trainees early to enhance the quality of consultation with individuals of alternate sexuality. ${ }^{35}$

Humans are social beings, and support from significant others can improve one's mental health. ${ }^{22}$ Receiving parental support in LGBTQI population is associated with a reduced risk of lifetime suicidal attempts, particularly in a younger population. ${ }^{22}$ A study involving Israeli gay and bisexual Jewish males with high levels of religiosity concluded that positive religious coping in the presence of social resources results in better mental health outcomes. ${ }^{36}$ Therefore, support from family and significant others improve mental health outcomes of individuals with conflict between their religious and sexual identities.

In addition, guidance from leaders or members of religious institutions is instrumental in resolving dilemma. Overall positive outcome is reported in LGBTQI youth who have opportunity to discuss their concerns with a supportive member of the religious community, even for the 'less accepting' religion; they are better at managing the conflict that arise between religious and LGBTQI identities. ${ }^{27}$ This can be accomplished by revising religious beliefs or re-interpreting religious scriptures with a peer or member of the religious community. It is important to foster a therapeutic relationship between an LGBTQI individual and a culturally competent and spiritually sensitive mental health professional who uses appropriate terminology, shows non-judgemental attitude, and recommends psychotherapy such as cognitive behavioural therapy. In this way, individuals with alternate sexuality may receive the respectful, sensitive, and effective care that they deserve. ${ }^{37}$

\section{Conclusions}

Individuals with conflict between their religious and sexual identities are at increased risk of mental health issues. Mental health outcomes can be improved by sufficient social support at home, school, or religious institutions. Mental health professionals and psychiatric trainees need to be educated on LGBTQI-related topics in order to provide optimal care.

\section{Declaration}

The authors have no conflict of interest to disclose.

\section{References}

1. Parliament of Australia. Sex discrimination amendment (sexual orientation, gender identity and intersex status) Act. 2013 No 98. Available from: https://www.legislation.gov.au/Details/C2013A00098. Accessed 22 May 2017.

2. Safi M. Campaigners celebrate as India decriminalises homosexuality. 2018. Available at: https://www.theguardian.com/world/2018/sep/06/ indian-supreme-court-decriminalises-homosexuality. Accessed 7 September 2018.

3. Hodge A, Rayda N. Sharia law in Aceh to face legal challenge. 2017. Available at: https://www.theaustralian.com.au/news/ world/sharia-law-in-aceh-to-be-face-legal-challenge/news-story/ c38c455121794660eeef2alea6b65c6f. Accessed 27 October 2017.

4. Halkitis PN, Mattis JS, Sahadath JK, Massie D, Ladyzhenskaya L, Pitrelli K, et al. The meanings and manifestations of religion and spirituality among lesbian, gay, bisexual, and transgender adults. J Adult Dev 2009;16:250-62. Crossref

5. McNeill JJ. Moral theology and homosexuality. In: The Church and the Homosexual. 4th ed. Massachusetts: Beacon Press; 2015: 29-30.

6. Cornwall S. 'State of mind' versus 'concrete set of facts': the contrasting of transgender and intesex in church documents on sexuality. Theol Sex 2015;15:7-28. Crossref

7. Rogers J. All are one in Christ Jesus. In: Jesus, the Bible and Homosexuality, Revised and Expanded Edition: Explode the Myths, 
Heal the Church. 1st ed. Kentucky: Westminster Knox Press; 2009:135-45.

8. Kligerman N. Homosexuality in Islam: a difficult paradox. Macalester Islam J 2007;2:53-64.

9. Boellstorff T. Between religion and desire: being Muslim and gay in Indonesia. Am Anthropol 2005;107:575-85. Crossref

10. Safavifar F, Eftekhar M, Alavi K, Negarandeh R, Jalali AH, Eftekhar M. Religious experiences of Iranian transgenders: a qualitative study. Med J Islam Repub Iran 2016;30:385.

11. Agoramoorthy G, Hsu MJ. Living on the societal edge: India's transgender realities. J Relig Health 2015;54:1451-9. Crossref

12. Mandair A. Sikhism. In: Sorajjakool S, Carr MF, Bursey E, Nam J, editors. World Religions for Healthcare Professionals. New York: Taylor \& Francis; 2009: 87-8.

13. Siker JS. Buddhism. In: Homosexuality and Religion: an Encyclopedia. Connecticut: Greenwood Press; 2007:8-9.

14. McGee RW. The relationship between religion and views towards homosexuality: an empirical study of 98 countries. 2016. Available at: https://ssrn.com/abstract=2799870. Accessed 6 May 2017.

15. Couch M, Mulcare H, Pitts M, Smith A, Mitchell A. The religious affiliation of gay, lesbian, bisexual, transgender and intersex Australians: a report from the Private Lives survey. People Place 2008;16:1-11.

16. Drescher J. Out of DSM: depathologizing homosexuality. Behav Sci (Basel) 2015;5:565-75. Crossref

17. American Psychiatric Association. Diagnostic and Statistical Manual of Mental Disorders. Arlington: American Psychiatric Publishing; 2013.

18. Cochran SD, Drescher J, Kismodi E, Giami A, Garcia-Moreno C, Atalla E, et al. Proposed declassification of disease categories related to sexual orientation in the International Statistical Classification of Disease and Related Health Problems (ICD-11). Bull World Health Organ 2014;92:672-9. Crossref

19. Mays VM, Cochran SD. Mental health correlates of perceived discrimination among lesbian, gay, and bisexual adults in the United States. Am J Public Health 2001;91:1869-76. Crossref

20. King M, Semlyen J, Tai SS, Killaspy H, Osborn D, Popelyuk D, et al. A systematic review of mental disorder, suicide, and deliberate self harm in lesbian, gay and bisexual people. BMC Psychiatry 2008;8:70. Crossref

21. Clements-Nolle K, Marx R, Guzman R, Katz M. HIV prevalence, risk behaviors, health care use, and mental health status of transgender persons: implications for public health intervention. Am J Public Health 2001;91:915-21. Crossref

22. Mustanski B, Liu RT. A longitudinal study of predictors of suicide attempts among lesbian, gay, bisexual, and transgender youth. Arch Sex Behav 2013;42:437-48. Crossref

23. Meyer IH. Prejudice, social stress, and mental health in lesbian, gay, and bisexual populations: conceptual issues and research evidence.
Psychol Bull 2003;129:674-97. Crossref

24. Lau H, Stotzer RL. Employment discrimination based on sexual orientation: a Hong Kong study. Employ Respons Rights J 2010.

25. Prajapati AC, Parikh S, Bala DV. A study of mental health status of men who have sex with men in Ahmedabad city. Indian J Psychiatry 2014;56:161-4. Crossref

26. Gibbs JJ, Goldbach J. Religious conflict, sexual identity, and suicidal behaviors among LGBT young adults. Arch Suicide Res 2015;19:47288. Crossref

27. Higa D, Hoppe MJ, Lindhorst T, Mincer S, Beadnell B, Morrison DM, et al. Negative and positive factors associated with the well-being of lesbian, gay, bisexual, transgender, queer, and questioning (LGBTQ) youth. Youth Soc 2014;46:663-87. Crossref

28. Hopwood RA, Witten TM. Spirituality, faith and religion: the transgender and gender nonconforming experience. In: Singh A, Dickey L, editors. Handbook of Trans-affirmative Counselling and Psychological Practice. 1st ed. Washington: American Psychological Association; 2017.

29. Lytle MC, De Luca SM, Blosnich JR, Brownson C. Associations or racial/ethnic identities and religious affiliation with suicidal ideation among lesbian, gay, bisexual, and questioning individuals. J Affect Disord 2015;178:39-45. Crossref

30. Gattis MN, Woodford MR, Han Y. Discrimination and depressive symptoms among sexual minority youth: is gay-affirming religious affiliation a protective factor? Arch Sex Behav 2014;43:158999. Crossref

31. Fredriksen-Goldsen KI, Cook-Daniels L, Kim HJ, Erosheva EA, Emlet CA, Hoy-Ellis CP, et al. Physical and mental health of transgender older adults: an at-risk and underserved population. Gerontologist 2014;54:488-500. Crossref

32. Rutherford K, McIntyre J, Daley A, Ross LE. Development of expertise in mental health service provision for lesbian, gay, bisexual and transgender communities. Med Educ 2012;46:903-13. Crossref

33. Lim RF, Koike AK, Gellerman DM, Seritan AL, Servis ME, Lu FG. A four-year model curriculum on culture, gender, LGBT, religion and spirituality for general psychiatry residency training programs in the United States; 2010.

34. Srikanth R, Pooja R, Meraj Q, Nishant O, Samir D, Ganpat V. Attitudes towards homosexuality among psychiatrists in India: a survey-based cross-sectional study. Arch Psychiatry Psychother 2016;3:32-9.

35. Kalra G. Sensitizing psychiatry trainees towards male homosexuality: a movie club approach. J Contemp Med Edu 2013;1:106-12. Crossref

36. Shilo G, Yossef I, Savaya R. Religious coping strategies and mental health among religious Jewish gay and bisexual men. Arch Sex Behav 2016;45:1551-61. Crossref

37. Bowland SE, Foster K, Vosler AN. Culturally competent and spiritually sensitive therapy with lesbian and gay Christians. Soc Work 2013;58:321-32. Crossref 